\title{
Estrogen Therapy
}

National Cancer Institute

\section{Source}

National Cancer Institute. Estrogen Therapy. NCI Thesaurus. Code C15483.

The use of estrogen in the treatment of any disease or disorder. 